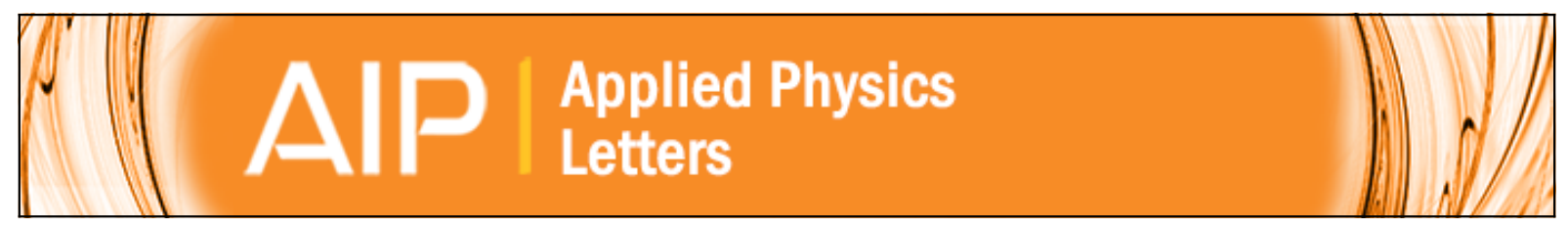

\title{
Ultrafast nonresonant third-order optical nonlinearity of fullerene-containing polyurethane films at telecommunication wavelengths
}

Qiying Chen, Li Kuang, Edward H. Sargent, and Zhi Yuan Wang

Citation: Applied Physics Letters 83, 2115 (2003); doi: 10.1063/1.1609660

View online: http://dx.doi.org/10.1063/1.1609660

View Table of Contents: http://scitation.aip.org/content/aip/journal/apl/83/11?ver=pdfcov

Published by the AIP Publishing

\section{Articles you may be interested in}

Plasmon resonance enhanced large third-order optical nonlinearity and ultrafast optical response in Au nanobipyramids

Appl. Phys. Lett. 105, 061903 (2014); 10.1063/1.4892887

Resonant enhancement of third-order nonlinear optical susceptibilities of Cd-free chalcopyrite nanocrystals within quantum confinement regime

Appl. Phys. Lett. 103, 053116 (2013); 10.1063/1.4817395

Ultrafast nonresonant third-order optical nonlinearities in ZnSe for photonic switching at telecom wavelengths Appl. Phys. Lett. 85, 4606 (2004); 10.1063/1.1823599

Enhanced third-order nonlinear optical properties of C 60 -silane compounds

Appl. Phys. Lett. 81, 2701 (2002); 10.1063/1.1512959

Large third-order optical nonlinearity in Au:TiO 2 composite films measured on a femtosecond time scale Appl. Phys. Lett. 72, 1817 (1998); 10.1063/1.121193

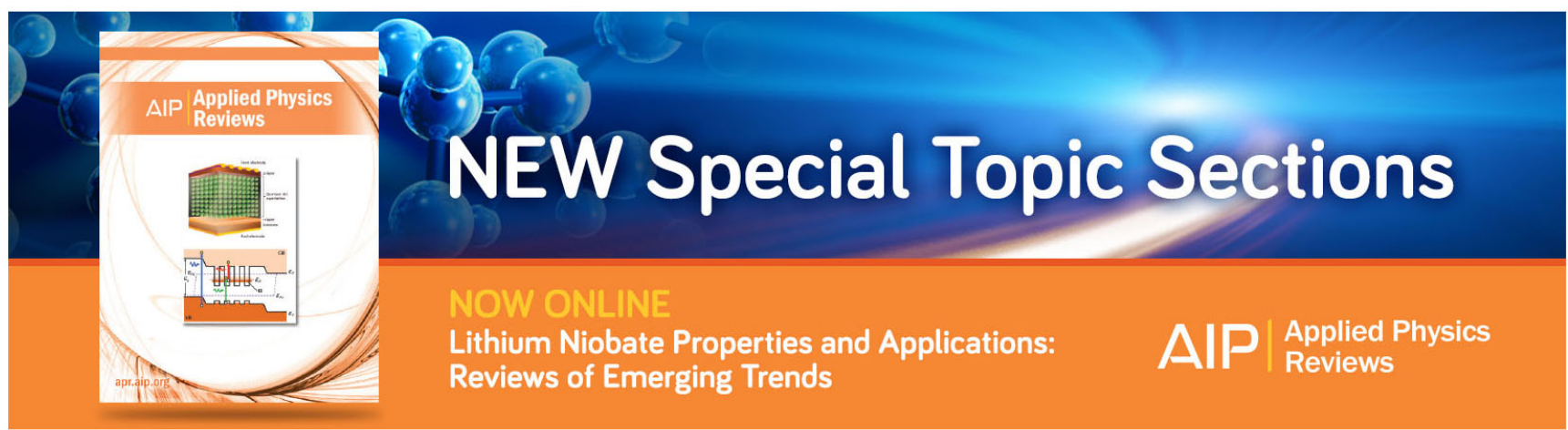




\title{
Ultrafast nonresonant third-order optical nonlinearity of fullerene- containing polyurethane films at telecommunication wavelengths
}

\author{
Qiying Chen ${ }^{\text {a) }}$ \\ Department of Electrical and Computer Engineering, University of Toronto, 10 King's College Road, \\ Toronto, Ontario M5S 3G4, Canada \\ Li Kuang \\ Department of Chemistry, Carleton University, 1125 Colonel By Drive, Ottawa, Ontario K1S 5B6, Canada \\ Edward H. Sargent \\ Department of Electrical and Computer Engineering, University of Toronto, 10 King's College Road, \\ Toronto, Ontario M5S 3G4, Canada \\ Zhi Yuan Wang \\ Department of Chemistry, Carleton University, 1125 Colonel By Drive, Ottawa, Ontario K1S 5B6, Canada
}

(Received 8 May 2003; accepted 16 July 2003)

\begin{abstract}
High-optical-quality polyurethane films containing a high load of $(60)$ fullerene $\left(\mathrm{C}_{60}\right)$ were prepared by reaction of the hydroxy-containing $\mathrm{C}_{60}$ and triisocyanate with the goal of obtaining enhanced nonresonant third-order optical nonlinearity. Optical nonlinearity was measured using the Z-scan technique in the wavelength range $1150-1600 \mathrm{~nm}$. This revealed a positive Kerr coefficient with nonresonant $n_{2}$ equal to $2.0( \pm 0.6) \times 10^{-3} \mathrm{~cm}^{2} / \mathrm{GW}$ and excellent linear-absorption and nonlinear-absorption figures of merit at $1550 \mathrm{~nm}$. The technique reported herein is a new approach to obtain fullerene films with the capacity to realize a high number density of $\mathrm{C}_{60}$ moieties. These resulted in more than 2 orders of enhancement in the third-order susceptibility over recently reported $\mathrm{C}_{60}$ sol and gel, and an enlarged second-order hyperpolarizability resulting from further enhanced charge transfer processes. (C) 2003 American Institute of Physics. [DOI: 10.1063/1.1609660]
\end{abstract}

Third-order nonlinear optical (NLO) phenomena of conjugated organic compounds and polymers are of great interest in optical switching and signal processing for their large optical nonlinearity and fast response time. ${ }^{1-6}$ However, few organic materials reported to date provide suitable nonlinearity (large nonresonant nonlinearity with response time of picoseconds or less) in the near infrared region.

The nonlinear refractive index $n_{2}\left(n=n_{0}+n_{2} I\right.$, where $n_{0}$ is the linear part of the refractive index and $I$ the incident intensity) may be enhanced through one- or two-photon resonant transitions. These are accessed when the absorption peak wavelength of the material lies sufficiently close to one or half of the operating wavelength. However, this resonant enhancement of $n_{2}$ is accompanied by optical loss due to absorption, described by $\alpha=\alpha_{0}+\beta I$, where $\alpha_{0}$ is the linear absorption coefficient and $\beta$ is the nonlinear absorption coefficient. The NLO efficiency/transparency tradeoff $\left(n_{2} / \alpha\right)$ at a specific wavelength is therefore of primary importance for assessing the suitability of a material for use in a device. This parameter is usually evaluated through two figures of merit: $W=n_{2} I / \alpha_{0} \lambda$ and $T=\beta \lambda / n_{2}$. According to the requirements mentioned above, it is necessary to achieve $W$ $\gg 1$ and $T \ll 1$.

Fullerenes (e.g., $\mathrm{C}_{60}$ ), a class of highly conjugated compounds, have attracted considerable research interest for their large and fast optical nonlinearities. ${ }^{7-12}$ Owing to the large

\footnotetext{
a) Author to whom correspondence should be addressed; present address: Integrated Manufacturing Technologies Institute, National Research Council of Canada, 800 Collip Circle, London, Ontario N6G 4X8, Canada; electronic mail: qiying.chen@nrc.ca
}

activity of $\mathrm{C}_{60}$ molecules with an abundance of delocalized $\pi$ electrons, the synthesis of chemically modified $\mathrm{C}_{60}$ derivatives has been used to improve the solubility of $\mathrm{C}_{60}$ in solution with the hope of achieving a strong NLO response. ${ }^{8,9,12}$ Previous research has been performed on $\mathrm{C}_{60}$ in solution. The nonlinear optical properties of fullerenes and their derivatives in solid-state films have not been well studied due to the difficulties in obtaining homogeneously mixed fullerene molecules in a matrix..$^{10-12}$

In this study, a high-quality film of crosslinked polyurethane containing a high content of covalently bonded $\mathrm{C}_{60}$ is studied using the Z-scan technique. The material was designed to achieve significant charge transfer with a high $\mathrm{C}_{60}$ concentration while retaining the highly delocalized $\pi$ electrons of $\mathrm{C}_{60}$ and good film-forming ability. This article reports on the third-order optical nonlinearity of fullerene derivatives cast into films in the wavelength range of 1150 $1600 \mu \mathrm{m}$.

Trihydroxyl-containing $\mathrm{C}_{60}\left(3 \mathrm{OH}-\mathrm{C}_{60}\right)$ was prepared with high yield and characterized by IR and UV-Vis-NIR spectroscopic methods. ${ }^{13}$ The hydroxyl groups in $3 \mathrm{OH}-\mathrm{C}_{60}$ can react with a triisocyanate compound, resulting in a crosslinked $\mathrm{C}_{60}$-containing polyurethane system (Fig. 1). Film formation and subsequent thermal cure were carried out as follows: $0.06 \mathrm{~g}$ of TMP (a triisocyanate derived from trimethylolpropane and xylylene diisocyanate) was mixed with $0.02 \mathrm{~g}$ of $3 \mathrm{OH}-\mathrm{C}_{60}$ in $0.3 \mathrm{~mL}$ of 1-methyl-2-pyrolidinone (NMP) at room temperature resulting in a $3 \mathrm{OH}-\mathrm{C}_{60}$ concentration of $25 \mathrm{wt} \%$ (19.1 wt \% for $\mathrm{C}_{60}$ moieties). After filtering through a microfilter (pore size: $0.2 \mu \mathrm{m}$ ), the solution 


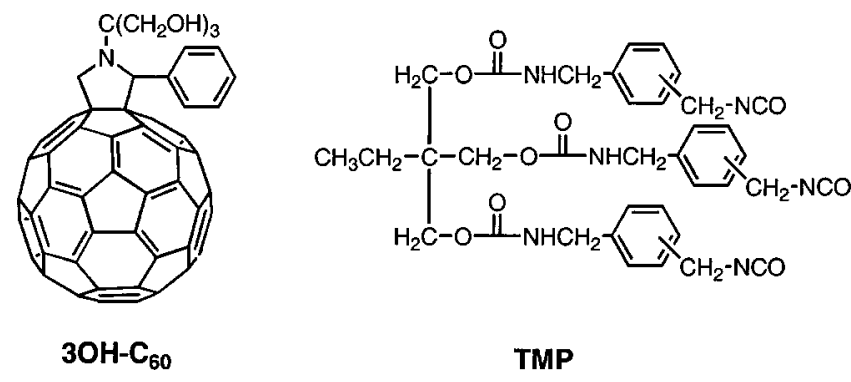

FIG. 1. Hydroxy-containing $\mathrm{C}_{60}\left(3 \mathrm{OH}-\mathrm{C}_{60}\right)$ and triisocyanate (TMP) used for preparation of crosslinked $\mathrm{C}_{60}$-containing polyurethane films.

was cast on glass plates. After drying overnight at $50^{\circ} \mathrm{C}$ under a nitrogen flow, the films were cured through the following heating steps: $1 \mathrm{~h}$ at $120^{\circ} \mathrm{C}, 1 \mathrm{~h}$ at $160^{\circ} \mathrm{C}$, and then $30 \mathrm{~min}$ at $210^{\circ} \mathrm{C}$. comparison of the absorption spectra of the film (thickness of $29.54 \mu \mathrm{m}$ ) and pristine $\mathrm{C}_{60}$ (Aldrich, 99.5\%) in toluene in the visible and near-infrared regions shows that the film possesses a broader absorption peak with a tail close to $700 \mathrm{~nm}$ while the pristine $\mathrm{C}_{60}$ in solution absorbs within the range of $270-400 \mathrm{~nm}$. It is known that $\mathrm{C}_{60}$ derivatives show weak or no characteristic absorption $\left(\lambda_{\max } 330 \mathrm{~nm}\right)$ of pristine $\mathrm{C}_{60}$, depending on the degree of substitution. ${ }^{14}$

The tunable laser for the measurement came from a picosecond Ti:sapphire amplified system with an optical parametric amplifier (Fig. 3), which produced output at pulsewidth $3.3 \mathrm{ps}$ and repetition rate $1 \mathrm{kHz}$. The description of the laser system and the measuremnet can be found elsewhere. ${ }^{15-17}$ Figure 2 shows the spectra of $n_{2}$ and $\beta$ in the wavelength range $1150-1600 \mathrm{~nm}$ measured consecutively at a wavelength interval of $50 \mathrm{~nm}$. At $1550 \mathrm{~nm}$, the openaperture curve does not show any valley or peak indicating that no nonlinear absorption exists $(\beta=0)$. Fitting with $\Delta \Phi_{0}$ and $z_{0}$ as variables yields $\Delta \Phi_{0}=0.43$ and $z_{0}=1.2 \mathrm{~mm}$. Following the relation $\Delta \Phi_{0}=2 \pi \Delta n L_{\text {eff }} / \lambda$, it is possible to obtain the refractive index change at the focal point $\Delta n=3.6$ $\times 10^{-3}$ and Kerr coefficient $n_{2}=2.0( \pm 0.6)$ $\times 10^{-3} \mathrm{~cm}^{2} / \mathrm{GW}$. In this wavelength region, the $n_{2}$ values lie between (1.6 and 2.4) $\times 10^{-3} \mathrm{~cm}^{2} / \mathrm{GW}$ while the $\beta$ values decrease from about $20 \mathrm{~cm} / \mathrm{GW}$ near $1150 \mathrm{~nm}$ to essen-

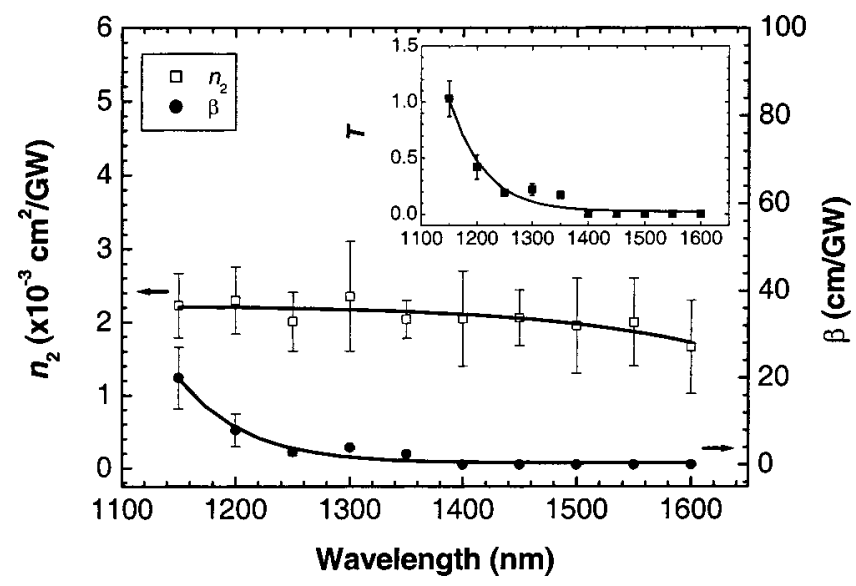

FIG. 2. Spectra of nonlinear refractive index $n_{2}$ and nonlinear absorption $\beta$ of the film in the wavelength range of $1150-1600 \mathrm{~nm}$. The inset shows the spectrum of the figure of merit $T$ in the corresponding wavelength range, Solid lines are the viewing guides. tially zero at wavelengths above $1400 \mathrm{~nm}$. Nonlinear absorption in the wavelength range $1150-1400 \mathrm{~nm}$ is attributable to multiphoton processes. Since the material exhibits negligible one-photon absorption $\alpha_{0}$ throughout this infrared region, the $W$ values are ideal, i.e., $W \gg 1$. Due to nonlinear absorption at the wavelengths near $1150 \mathrm{~nm}$, the $T$ values near 1150 $\mathrm{nm}$ are marginal. However, $T$ values are satisfactory near $1550 \mathrm{~nm}$ (see inset in Fig. 2).

The nonlinear refractive index and nonlinear absorption coefficient are related to the real part $\left(\operatorname{Re}\left[\chi^{(3)}\right]\right)$ and imaginary part $\left(\operatorname{Im}\left[\chi^{(3)}\right]\right)$ of the third-order nonlinear optical susceptibility through the equations $\mathrm{s}^{2,17}$

$$
\begin{aligned}
& \operatorname{Im}\left[\chi^{(3)}\right]=\frac{2 \varepsilon_{0} c^{2} n_{0}^{2}}{3 \omega} \beta, \\
& \operatorname{Re}\left[\chi^{(3)}\right]=\varepsilon_{0} c n_{0}^{2} n_{2}, \\
& \chi^{(3)}=\operatorname{Re}\left[\chi^{(3)}\right]+i \operatorname{Im}\left[\chi^{(3)}\right],
\end{aligned}
$$

where $c$ is the speed of light in vacuum, and $\varepsilon_{0}$ is the permittivity of free space. $n_{2}, \beta$, and $\chi^{(3)}$ in these equations are in SI units with the units of $\mathrm{m}^{2} \mathrm{~W}^{-1}, \mathrm{~m} / \mathrm{W}$, and $\mathrm{m}^{2} \mathrm{~V}^{-2}$, respectively. The calculated $\chi^{(3)}$ values, mostly contributed from $\operatorname{Re}\left[\chi^{(3)}\right]$, fall in the range of $(1.13-1.54)$ $\times 10^{-18} \mathrm{~m}^{2} \mathrm{~V}^{-2}$ with a value of $1.36 \times 10^{-18} \mathrm{~m}^{2} \mathrm{~V}^{-2}(9.74$ $\left.\times 10^{-11} \mathrm{esu}\right)$ at $1550 \mathrm{~nm}$.

The molecular second-order hyperpolarizability $\gamma$ in isotropic media is related to $\chi^{(3)}$ by

$$
\gamma=\frac{\chi^{(3)}}{N L},
$$

where $N$ is the number density of the molecule, and $L$ is the local field correction factor, expressed as $\left[\left(n^{2}+2\right) / 3\right]^{4}$ under the Lorentz-Lorenz approximation with the refractive index $n$. Using Eq. (4), we may estimate the value of $\gamma$ for $\mathrm{C}_{60}$ moieties. From the measured refractive index of 1.60 and the calculated number density of $1.9 \times 10^{20} \mathrm{~cm}^{-3}$, the $\gamma$ value for the $\mathrm{C}_{60}$ moieties in our sample is $\sim 9.6 \times 10^{-32}$ esu at $1550 \mathrm{~nm}$, which is 2.7 times the $\gamma$ value of $\mathrm{C}_{60}\left[\left(\mathrm{NH}_{2}\right)_{2} \mathrm{CNCN}\right]_{5}$ solution $\left(3.5 \times 10^{-32} \mathrm{esu}\right)$ and 9.6 times the value of $\mathrm{C}_{60}\left(\mathrm{NH}_{2} \mathrm{CN}\right)_{5}$ solutions (1.0 $\times 10^{-32}$ esu).$^{9}$

Since $\mathrm{C}_{60}$ possesses regularly alternated hexagonal and pentagonal rings and poorly delocalized symmetric double bonds, its highly symmetric structure blocks most of transition pathways from the ground state to the excited states. By breaking double bonds and attaching an electron donor group, the $\mathrm{C}_{60}$ derivatives, with the alternated electron symmetry of $\mathrm{C}_{60}$ molecules by the introduced electrons, show prominent enhancement on the optical nonlinearity, as compared with pristine $\mathrm{C}_{60}$. The mechanism for the significant enhancement in our case is believed to be due to a strong charge transfer process in which $\mathrm{C}_{60}$ moiety acts as an electron acceptor and the substitute group or polymeric host serves as an electron donor. Reported techniques on the incorporation of $\mathrm{C}_{60}$ in solid state have been mainly focused on the doping into glasses or sol-gel techniques. However, restricted by crack formation at higher $\mathrm{C}_{60}$ concentration $(\sim 0.1 \mathrm{wt} \%)$, the feasible doping levels reported were quite low $(0.01-0.1 \mathrm{wt} \%) .{ }^{11}$ The successful incorporation of large amount $(19.1 \mathrm{wt} \%)$ of $\mathrm{C}_{60}$ moleties into a highly 
TABLE I. Comparison of third-order optical nonlinearity of $\mathrm{C}_{60}$-containing polyurethane film in this study with previous studies on $\mathrm{C}_{60}$ derivatives.

\begin{tabular}{|c|c|c|c|c|c|}
\hline $\begin{array}{l}\text { Reference and } \\
\text { measurement } \\
\text { wavelength }\end{array}$ & Material & Concentration & $\begin{array}{l}\text { Number } \\
\text { density } \\
\left(\mathrm{cm}^{-3}\right)\end{array}$ & $\begin{array}{l}\chi^{(3)} \\
\text { (esu) }\end{array}$ & $\begin{array}{c}\gamma \\
\text { (esu) }\end{array}$ \\
\hline \multirow[t]{2}{*}{$\begin{array}{l}\text { Ref. } 8 \\
(\sim 452 \mathrm{~nm})\end{array}$} & Neutral species solution & $7-27 \mathrm{mM}$ & $\begin{array}{l}(4.2-16.2) \times 10^{18} \\
\text { (ca.) }\end{array}$ & $<5.8 \times 10^{-15}$ & $\begin{array}{l}<3.7( \pm 1.5) \times 10^{-35} \\
\text { (ca.) }\end{array}$ \\
\hline & Anionic $\mathrm{C}_{60}$ solution & $1.3-4.5 \mathrm{mM}$ & $\begin{array}{l}(0.8-2.7) \times 10^{18} \\
(\text { ca. })\end{array}$ & - & $2.4( \pm 1.0) \times 10^{-33}$ \\
\hline Ref. 9 & $\mathrm{C}_{60}\left(\mathrm{NH}_{2} \mathrm{CN}\right)_{5}$ solution & $3 \mathrm{mM}$ & $1.8 \times 10^{18}$ (ca.) & $5.8 \times 10^{-14}$ & $1.0 \times 10^{-32}$ \\
\hline$(830 \mathrm{~nm})$ & $\mathrm{C}_{60}\left[\left(\mathrm{NH}_{2}\right)_{2} \mathrm{CNCN}\right]_{5}$ solution & $1.0 \mathrm{mM}$ & $6.0 \times 10^{17}$ (ca.) & $6.8 \times 10^{-14}$ & $3.5 \times 10^{-32}$ \\
\hline Ref. 12 & $\mathrm{C}_{60^{-}}$-silane sol & $1.6 \mathrm{mM}$ & $9.6 \times 10^{17}$ (ca.) & $1.4 \times 10^{-13}$ & - \\
\hline$(820 \mathrm{~nm})$ & $\mathrm{C}_{60}$-silane gel & $1.6 \mathrm{mM}$ & $9.6 \times 10^{17}$ (ca.) & $1.6 \times 10^{-13}$ & - \\
\hline $\begin{array}{l}\text { This study } \\
(1550 \mathrm{~nm})\end{array}$ & $\begin{array}{l}\text { Crosslinked } \mathrm{C}_{60^{-}} \\
\text {polyurethane film }\end{array}$ & $19.1 \mathrm{wt} \%$ & $1.9 \times 10^{20}$ & $9.7 \times 10^{-11}$ & $9.6 \times 10^{-32}$ \\
\hline
\end{tabular}

(ca.), data calculated from the information in the references; - , data unavailable.

crosslinked polymeric system achieving a high number density of $\mathrm{C}_{60}$ moieties is crucial to realize the significant increase of $\chi^{(3)}$ values in this study over those of chargetransferred $\mathrm{C}_{60}$ reported elsewhere. ${ }^{7-12}$ A comparison of the third-order optical nonlinearity obtained in this study with previous studies is given in Table I. It is shown that the $\chi^{(3)}$ value of $\mathrm{C}_{60}$-containing polyurethane film herein provides a more than 2 orders of magnitude enhancement over recently reported $\mathrm{C}_{60}-$ siliane sol and gel. The discrepancy in the values of $\gamma$ between our measurements and those reported previously comes mainly from the different behaviors of electron donors, which result in the different extents of the charge transfer processes. It was reported that it is possible for the magnitude of $\chi^{(3)}$ for $\mathrm{C}_{60}$ with different electron donors to vary near one order magnitude. ${ }^{12}$ One of the starting materials $\left(3 \mathrm{OH}-\mathrm{C}_{60}\right)$ in our synthesis before crosslinking process was trihydroxyl-containing $\mathrm{C}_{60}$, which was a charge transfer $\mathrm{C}_{60}$ complex with similar molecular structures as the charge transfer $\mathrm{C}_{60}$ complexes reported previously. Our crosslinking process is a new technique, which realizes a high number density of $\mathrm{C}_{60}$ moieties, further enhance the charge transfer processes of the materials, and render the possibility to fabricate high-quality uniform films. We believe the enhanced charge transfer processes with crosslinking in this study accounts for the enhancement of $\gamma$ values. Our results confirmed some foresights of Lascola et al. that $\mathrm{C}_{60}^{-} \chi^{(3)}$ can be optimized by derivatization, choice of matrix, and reduction to lower valence states, and charged fullerenes can have bulk nonlinearities that are comparable to the best organic materials, ${ }^{8}$ for example, polydiacetylene-based polymer PTS ( $p$-toluene sulfonate) $\left(\chi^{(3)}=5 \times 10^{-10}\right.$ esu) ${ }^{18}$ and recently reported single-crystal PTS $\quad\left[n_{2}=2.2( \pm 0.3)\right.$ $\left.\times 10^{-12} \sim 5( \pm 1) \times 10^{-12} \mathrm{~cm}^{2} / \mathrm{W}\right] .^{6,19}$

In summary, third-order optical nonlinearity of conjugated crosslinked $\mathrm{C}_{60}$-containing polyurethane films with the enhancement of nonlinearity by the charge transfer process is investigated and found to possess ultrafast nonresonant nonlinearity around $1550 \mathrm{~nm}$ with excellent figures of merit. Molecular engineering is effective in manipulating the optical properties of the materials and overcoming the low solubility of pristine $\mathrm{C}_{60}$ to fabricate high-quality films with high number density of $\mathrm{C}_{60}$ moieties. It results in large third-order susceptibility and the second-order hyperpolarizability from the enhanced charge transfer processes via crosslinking. The spectral dependence of the third-order optical nonlinearity over a wide infrared wavelength range informs structureproperty relationships ${ }^{20}$ and in the range $1300-1600 \mathrm{~nm}$, is pertinent to applications in optical signal processing in communication systems.

${ }^{1}$ M. Bass, J. M. Enoch, E. W. V. Stryland, and W. L. Wolfe, Handbooks of Optics IV, Fiber Optics and Nonlinear Optics, 2nd ed. (McGraw-Hill, New York, 2001).

${ }^{2}$ M. G. Kuzyk and C. W. Dirk, Characterization Techniques and Tabulations for Organic Nonlinear Optical Materials (Marcel Dekker, New York, 1998).

${ }^{3}$ R. R. Tykwinski, U. Gubler, R. E. Martin, F. Diederich, C. Bosshard, and P. Gunter, J. Phys. Chem. 102, 4451 (1998).

${ }^{4}$ A. D. Slepkov, F. A. Hegmann, Y. Zhao, R. R. Tykwinski, and K. Kamada, J. Chem. Phys. 116, 3834 (2002).

${ }^{5}$ L. Yang, R. Dorsinville, R. Alfano, W. Zou, and N. Yang, Opt. Lett. 16, 758 (1991).

${ }^{6}$ G. I. Stegeman and W. E. Torruellas, Philos. Trans. R. Soc. London, Ser. A 354, 645 (1996).

${ }^{7}$ Q. H. Gong, Y. X. Sun, Z. J. Xia, Y. H. Zhou, Z. N. Gu, X. Zhou, and D. Qiang, J. Appl. Phys. 71, 3025 (1992).

${ }^{8}$ L. Geng and J. C. Wright, Chem. Phys. Lett. 249, 105 (1996); R. Lascola and J. C. Wright, ibid. 269, 79 (1997).

${ }^{9}$ S. Wang, W. Huang, R. Liang, Q. Gong, H. Li, H. Chen, and D. Qiang, Phys. Rev. B 63, 153408 (2001).

${ }^{10}$ R. Signorini, M. Meneghetti, R. Bozio, G. Brusayin, P. Innocenzi, M. Guglielmi, and F. D. Negra, J. Sol-Gel Sci. Technol. 22, 245 (2001).

${ }^{11}$ H. Zeng, Z. Sun, Y. Segawa, F. Lin, S. Mao, and Z. Xu, J. Appl. Phys. 89, 6539 (2001)

${ }^{12}$ B. L. Yu, H. P. Xia, C. S. Zhu, and F. X. Gan, Appl. Phys. Lett. 81, 2701 (2002)

${ }^{13}$ Z. Y. Wang and L. Kuang (unpublished).

${ }^{14}$ Z. Y. Wang, L. Kuang, X. S. Meng, and J. P. Gao, Macromolecules 31, 5556 (1998).

${ }^{15}$ Q. Chen, E. H. Sargent, N. Leclerc, and A. J. Attias, Appl. Phys. Lett. 82, 4420 (2003).

${ }^{16}$ M. Sheik-Bahae, A. A. Said, T. H. Wei, D. J. Hagan, and E. W. Van Stryland, IEEE J. Quantum Electron. 26, 760 (1990).

${ }^{17}$ A. A. Said, T. Xia, D. J. Hagan, E. W. Van Stryland, and M. Sheik-Bahae, J. Opt. Soc. Am. B 14, 824 (1997).

${ }^{18}$ G. M. Carter, Y. J. Chen, M. F. Rubner, D. J. Sandman, M. K. Thakur, and S. K. Tripathy, in: Nonlinear Optical Properties of Organics Molecules and Crystals, edited by D. S. Chemla and J. Zyss (Academic, New York, 1987), Vol. 2, p. 85.

${ }^{19}$ B. L. Lawrence, M. Cha, W. E. Torruellas, G. I. Stegeman, S. Etemad, G. Baker, and F. Kajzar, Appl. Phys. Lett. 64, 2773 (1994).

${ }^{20}$ T. W. Hagler and A. J. Heeger, Chem. Phys. Lett. 189, 333 (1992). 